\title{
Anthropometric correlates of morning plasma cortisol level and hormonal and biochemical response to fasting in obese
} premenopausal women

\author{
Vladimir N Melnikov ${ }^{1 *}$ and Lena B Kim ${ }^{2}$ \\ ${ }^{1}$ Institute of Physiology and Basic Medicine, Novosibirsk, Russia \\ ${ }^{2}$ Institute of Experimental and Clinical Medicine, Novosibirsk, Russia
}

\begin{abstract}
Numerous studies have established associations between hormonal parameters and body shape but they focused on the patterns of body fat distribution and, mainly, abdominal fat deposition. Based on the anthropometric features of patients with Cushing's syndrome, we hypothesized that there are somatometric predictors, other than waist-to-hip ratio, of increased cortisol production. To test this hypothesis and to identify the indicators of endocrine and metabolic responsiveness to shortterm fasting, we searched associations among 37 anthropometric traits and metabolic and hormonal parameters. An observational repeated measures study was performed on 64 moderately obese women using the partial correlation analysis. Blood glucose, serum lipids and urea concentrations, morning plasma cortisol, serum triiodthyronine (T3), thyroxin levels, and insulin activity (IRI) were examined before and after 4- and 7-day total fasting. The morning plasma cortisol level (RIA) showed the strongest correlation, independent of total fatness, with chest-hip circumference ratio $(\mathrm{CHR})(\mathrm{r}=0.48, \mathrm{p}<0.005)$, whereas no significant association could be found with waist-hip ratio (WHR). IRI level correlated directly with WHR ( $r=0.47, \mathrm{p}<0.001)$. The 4-day fasting significantly raised cortisol levels (+23\%), free fatty acids (FFAs) (+79\%), and triglyceride (TGs) (+34\%) concentrations, and lowered IRI (-43\%), T3 (-33\%) and glucose ( $-27 \%)$ levels. The cortisol response to 4-day fasting tended to relate with age $(r=0.25)$ and age-independently correlated with body height $(r=-0.30)$ and WHR ( $r=-0.27)$. Both basal levels and fast changes in glucose and TGs concentrations correlated with age (glucose, $r=0.38$; TGs, $r=0.24$; d-glucose, $r=-0.32$; $d-T G, r=-0.24$ ). The relative weight loss after the 27-day weight-loss program increased with increasing basal FFAs and thyroxin levels. In conclusion, CHR was found to be a powerful predictor for morning plasma cortisol level. The relation established seems to reflect the differential sensitivity of the upper and lower body subcutaneous adipocytes to the metabolic stimuli of the hormone and/or other factors associated with glucocorticoids.
\end{abstract}

\section{Introduction}

Since the early observation of J.Vague [1], numerous studies have demonstrated that high waist-to-hip circumference ratio (WHR), an indicator of android or abdominal body fat distribution (BFD), is a predictor or risk factor of diabetes mellitus [2], cardiovascular diseases and their complications [3]. The visceral type of obesity is associated with impaired insulin [4] and androgens [5] secretion and responsiveness. A relation was found between body dimensions and thyroid [6] and sex hormone levels [7].

The function of hypothalamic-pituitary-adrenal (HPA) axis was also shown to be related to the type of BFD [8-10]. Thus, the hyperactivity of the axis occurred in obese women with high WHRs after the administration of CRF and ACTH [11,12]. Increased cortisol responsiveness was also observed in women with abdominal type of obesity after adrenal stimulation by physical and mental stress [13] but diminished cortisol response was found in oral glucose tolerance test in men [14]. It is a wonder that in all these investigations the WHR and abdominal visceral-to-subcutaneous fat ratio [15] were the only examined somatometric indices [16] a priori being considered the most powerful predictors of HPA axis activity [17].

In the present study, we investigated a wide set of anthropometric variables in order to screen and choose specific signs, other than WHR, for the increased secretory patterns and metabolic stress responsiveness of adrenals as assessed by the morning plasma cortisol level. In addition to this primary objective, there were two aims: (1) to describe anthropometric correlates for the response of endocrine variables and the patterns of protein, glucose, and lipid metabolism to short-term fasting, and (2) to verify hormonal, metabolic and somatometric predictors for the weight reduction during weight-loss program (WLP). Taking into account the sex-dependence of cortisol metabolism in obesity [18] we performed this research on obese women who were usually being investigated from the standpoint under study.

\section{Subjects and methods}

\section{Subjects}

The study was undertaken on 64 Russian fertile women living in Novosibirsk city and referred to the endocrine division of the academic clinic for treatment of obesity by a WLP. The patients' free and informed consent to participate in the study was obtained. No women had signs of hirsutism, other endocrine disorders, heart disease, all

Correspondence to: Vladimir N Melnikov, Institute of Physiology and Basic Medicine, P.O. Box 237, Novosibirsk, 630117, Russia, Tel: +7-383 335 9556; E-mail: mevlanic@yandex.ru

Key words: body fat distribution, cortisol, fasting, obesity

Received: October 22, 2017; Accepted: November 24, 2017; Published: November 29, 2017 
were gynaecologically healthy and had a regular menstrual cycle. None of the patients had received hormonal therapy, oral contraceptives three months before the examination or other drugs known to effect endocrine function or glucose and lipid metabolism. The data were collected over the period of November-March.

The subjects were biochemically examined before and after 4 and 7 days of fast period $(0 \mathrm{Kcal})$ in order to evaluate the changes in hormonal and metabolic variables and to choose the informative point in time for assessing the mostly pronounced stress responsiveness.

The WLP consisted of a 7-day period of fasting and a consequent 20-day period of everyday aerobic physical load combined with a calorie restricted diet $(800 \mathrm{Kcal}$ a day). The exercise was performed on cycle ergometer for 30-40 min and corresponded to $25 \%$ of maximal oxygen consumption preliminarily determined at baseline in graded ergometer test using the Spirolyt-2 gas-analyzer (Germany). The effectiveness of WLP was assessed by the weight reduction at the end of 27-day treatment course in comparison with the initial state. During the fast period, patients had free access to water.

\section{Anthropometry}

Anthropometric measurements were taken before treatment by the same observer in a standing position of a person. A battery of 29 head and body dimensions were measured: maximum head length, stature, chin height, suprasternale height, umbilical height, greater trochanter height (leg length); biacromial breadth, chest breadth, bimammilary diameter, pelvic breadth, bitrochanter breadth; neck girth, chest girth, waist girth, hip girth, upper arm girth relaxed, forearm girth, thigh girth; ten-site skinfold thicknesses, and body weight (BW).

Based on these measurements the following indices were computed: BMI, head length-to-stature ratio, leg length-to-stature ratio (LLSR), biacromial index (BAI, biacromial breadth-stature ratio), bitrochanter index (BTI, bitrochanter breadth-stature ratio). Body fat (BF, percentage of BW) was calculated according to the method of Durnin and Womersley [19]. BFD patterns were evaluated by chestto-waist, chest-to-hip, and waist-to-hip circumference ratios (CWR, CHR, and WHR).

Skinfold thicknesses measurements were taken on the right side of the body to the nearest $0.1 \mathrm{~mm}$ using standard calibrated caliper. Chest circumference was measured by flexible steel tape at the level over the upper margin of breast in a relaxed state after moderate expiration; waist measurement was obtained at the minimum value between the iliac crest and the lateral cost margin; hip girth was measured at the level of the greater trochanters.

\section{Hormones and biochemistry}

Venous blood samples were taken regardless of the phase of the menstrual cycle between 8.00 and 9.00 AM after overnight fasting and were immediately used to obtain serum and plasma. The serum concentration of urea was measured using a commercially available test kit (Lakhena, Czech Republic), the blood glucose level was determined by the ortho-toluidine method. Serum triglycerides (TGs) [20], free fatty acids (FFA) [21], and total cholesterol (TC, method of Ilc) levels were measured in the same blood sample.

We used a commercially available specific RIA kit to determine the plasma cortisol level ("Sterone-J-125-M", a product of the Institute of Bioorganic Chemistry of the Byelorussian Academy of Sciences). Serum concentrations of triiodthyronine (T3), thyroxin (T4) and immunoreactive insulin (IRI) were also measured by RIA using test kits. General data for the sample are reported in Table 1.
Table 1. Baseline characteristics of subjects, $n=64$

\begin{tabular}{|c|c|c|c|}
\hline Parameter & Mean & \pm SD & Median \\
\hline Age, $\mathrm{yr}$ & 31.1 & 9.2 & 31.2 \\
\hline Body height, $\mathrm{cm}$ & 167.9 & 5.7 & 168.5 \\
\hline Body weight, $\mathrm{kg}$ & 97.5 & 14.9 & 95.2 \\
\hline BMI, $\mathrm{kg} / \mathrm{m}^{2}$ & 34.8 & 5.2 & 34.5 \\
\hline Body fat, $\%$ BW & 41.3 & 7.6 & 40.6 \\
\hline CHR & 0.86 & 0.05 & 0.87 \\
\hline WHR & 0.82 & 0.04 & 0.81 \\
\hline
\end{tabular}

\section{Statistical analysis}

Distributions of all variables were compared with the normal one according to the Kolmogorov-Smirnov criterion, and logarithmic transformation was applied to the abnormally distributed parameters. Transformation was only for statistical inferences and the data presented are untransformed raw data. A two-sided p-value $\leq 0.05$ was taken as the statistical significance. However, $\mathrm{p}<0.1$ was also indicated as an evidence of a tendency. Coefficients of correlation were calculated using linear regression analysis. Since body dimensions and BFD patterns are known to be age-dependent [22], and an inverse relation has been verified in obese women between the cortisol level and the amount of body fat [18], we computed partial correlation coefficients (age, BMI=const) in order to eliminate the influence of these factors on the relations between hormonal, metabolic variables and anthropometric traits. In order to evaluate the response of the parameters to fasting, the difference delta) between fast values and the respective baselines were calculated, and the paired t-test was used to compare the data. Since the delta-values were predominantly nonnormally distributed, Spearman rank order correlation coefficients were computed to evaluate the associations between fast changes in hormonal and metabolic variables and the anthropometric characters. Values are expressed as Mean \pm SD.

\section{Results}

\section{Anthropometric characteristics of subjects}

Women from the sample averaged $167.9 \pm 5.7 \mathrm{~cm}$ in height and were overweight and moderately obese (body weight, range, 72.0 to $128.1 \mathrm{~kg}$; BMI, range, 29.4 to $48.7 \mathrm{~kg} / \mathrm{m}^{2}$ ).

In the sample, age was directly and significantly correlated with BMI $(\mathrm{r}=0.37, \mathrm{p}<0.005)$, BTI $(\mathrm{r}=0.29, \mathrm{p}<0.03)$, and inversely associated with LLSR $(r=-0.56, p<0.001)$ and CWR $(r=-0.36, p<0.01)$. The significant positive relations of BMI with BTI $(r=0.69, p<0.0001)$, \% body fat $(\mathrm{r}=0.58, \mathrm{p}<0.0005), \mathrm{BAI}(\mathrm{r}=0.26, \mathrm{p}<0.05)$ and negative correlations with LLSR $(r=-0.68, p<0.0001)$ and CWR $(r=-0.35, p<0.01)$ were observed.

A statistical analysis of CHR, which was found to be the most powerful predictor for cortisol levels in the examined population, revealed that the parameter is age-independent $(\mathrm{r}=0.19, \mathrm{p}>0.05[\mathrm{~ns}])$ and that the observed distribution did not differ from the normal one according to the Kolmogorov-Smirnov test and seemed to be shifted to the left ranging from 0.80 to 0.95 . The CHR distribution in a control group of 18 non-obese healthy women $\left(B M I=23.4 \pm 0.4 \mathrm{~kg} / \mathrm{m}^{2}\right)$ was characterized by the similar mean value 0.87 , but lower indices of variability, $\mathrm{SD}=0.021$, as compared with the obese subjects.

CHR was marginally associated with body weight $(r=-0.20$, $\mathrm{p}<0.07), \mathrm{BF}(\mathrm{r}=-0.23, \mathrm{p}<0.06)$ and somewhat more closely associated with BMI $(r=-0.26, p<0.05)$. Similarly, CWR inversely correlated with $\mathrm{BMI}(\mathrm{r}=-0.35, \mathrm{p}<0.005)$. These findings suggest that more obese women have a predominant gluteo-femoral and abdominal fat preponderance 
whereas the less obese subjects have an upper-trunk deposition. A weak inverse correlation between CHR and BTI $(r=-0.35, p<0.01)$, however, disappeared after adjusting for the effects of BMI in a partial correlation analysis because of the strong direct correlation between the BTI and BMI. No relation could be found between BMI and WHR $(\mathrm{r}=0.23, \mathrm{~ns})$ in these women.

\section{Association patterns between baseline hormonal, metabolic variables and body dimensions}

\section{Cortisol}

All individual plasma cortisol levels in the sample were within the normal limits and ranged between 216 and $690 \mathrm{nmol} / \mathrm{L}$ thereby excluding cortico-adrenal dysfunction. Coefficients of partial correlation between the cortisol concentrations and anthropometric variables and indices are presented in Table 2.

An age-independent relation could be observed between the morning cortisol levels and $\mathrm{BMI}(\mathrm{r}=-0.33, \mathrm{p}<0.02)$. The correlations

Table 2. Coefficients of partial correlation (age, BMI=const) between morning plasma cortisol levels and anthropometric variables and indices in moderately obese premenopausal women $(n=64)$.

\begin{tabular}{|c|c|c|}
\hline Variable & $\mathrm{r}$ & $\mathrm{P}$ \\
\hline Head length & -0.11 & 0.417 \\
\hline Stature & 0.28 & 0.044 \\
\hline Chin height & 0.29 & 0.047 \\
\hline Suprasternale height & 0.30 & 0.048 \\
\hline Umbilical height & 0.29 & 0.040 \\
\hline $\begin{array}{l}\text { Greater trochanter height } \\
\text { (leg length) }\end{array}$ & 0.36 & 0.009 \\
\hline Biacromial breadth & -0.11 & 0.460 \\
\hline Chest breadth & 0.11 & 0.352 \\
\hline Bimammilary diameter & 0.08 & 0.480 \\
\hline Pelvic breadth & -0.11 & 0.330 \\
\hline Bitrochanter breadth & -0.26 & 0.058 \\
\hline Neck girth & 0.15 & 0.355 \\
\hline Chest girth & 0.16 & 0.112 \\
\hline Waist girth & 0.05 & 0.604 \\
\hline Hip girth & -0.09 & 0.320 \\
\hline Upperarm girth (relax) & 0.18 & 0.122 \\
\hline Forearm girth & 0.08 & 0.520 \\
\hline Thigh girth & 0.09 & 0.480 \\
\hline \multicolumn{3}{|l|}{ Skinfold thicknesses } \\
\hline Cheek & 0.11 & 0.381 \\
\hline Mental & 0.13 & 0.350 \\
\hline Suprailiac & 0.09 & 0.482 \\
\hline Subscapular & 0.14 & 0.182 \\
\hline Upperarm (biceps) & 0.13 & 0.220 \\
\hline Upperarm (triceps) & 0.15 & 0.160 \\
\hline Forearm & 0.08 & 0.551 \\
\hline Hand (posterior) & 0.02 & 0.621 \\
\hline Thigh & -0.03 & 0.482 \\
\hline Calf & 0.02 & 0.560 \\
\hline Body weight & -0.21 & 0.121 \\
\hline Body fat, $\%$ & -0.05 & 0.705 \\
\hline Chest-waist ratio & 0.16 & 0.078 \\
\hline Chest-hip ratio & 0.48 & 0.005 \\
\hline Waist-hip ratio & 0.04 & 0.762 \\
\hline Head length-stature ratio & -0.25 & 0.076 \\
\hline Leg length-stature ratio & 0.18 & 0.061 \\
\hline Biacromial breadth-stature ratio & -0.20 & 0.154 \\
\hline Bitrochanter breadth-stature ratio & -0.31 & 0.024 \\
\hline
\end{tabular}

with LLSR $(\mathrm{r}=0.30, \mathrm{p}<0.03)$ and CWR $(\mathrm{r}=0.28, \mathrm{p}<0.05)$ became weak and nonsignificant after adjusting for BMI values. CHR showed the stronger and more consistent correlation $(r=0.52, p<0.001)$ than other anthropometric characters studied; the relation remained significant when the effects of BMI were controlled by using a partial correlation analysis $(\mathrm{r}=0.48, \mathrm{p}<0.005)$. The relation is characterized by the equation of regression CORT $=1085+1860^{\star} \mathrm{CHR}$ and by the equation of partial regression $\mathrm{CORT}=2520+4210^{*} \mathrm{CHR}$ after controlling for the influence of BMI in the bivariate regression analysis. The cortisol levels in the lowest $(\mathrm{CHR} \leq 0.83)$ and highest $(\mathrm{CHR} \geq 0.90)$ quartiles were $343 \pm 82$ $\mathrm{nmol} / \mathrm{L}$ and $605 \pm 67 \mathrm{nmol} / \mathrm{L}$, respectively $(\mathrm{p}<0.01)$.

Chest girth and hip girth separately, as well as subscapular-tothigh and subscapular-to-suprailiac skinfold ratios do not correlate with the cortisol ( $\mathrm{p}=\mathrm{ns}$ in all these cases). We can also exclude the bone components of chest and pelvic size from consideration because of the lack of association of cortisol levels with chest breadth, biacromial breadth, pelvic breadth, bitrochanter breadth, and chest breadthbitrochanter breadth ratio. Zero correlation was observed between the cortisol levels and WHRs.

Regarding the direction of associations, marked differences between the longitudinal and transverse body dimensions can be stated although some correlation coefficients are not statistically significant. As it is shown in table 2, the cortisol level demonstrates the direct correlations with leg length $(\mathrm{r}=0.36)$, umbilical height $(\mathrm{r}=0.30)$, suprasternale height $(\mathrm{r}=0.30)$, chin height $(\mathrm{r}=0.29)$, and stature $(\mathrm{r}=0.28)$, indicating the decreasing associations, but it demonstrates the inverse correlations with bitrochanter breadth $(\mathrm{r}=-0.26)$, pelvic breadth $(\mathrm{r}=-0.10)$, and biacromial breadth $(\mathrm{r}=-0.10)$, i.e. with transverse body measurements and with the respective indices. Furthermore, among longitudinal measurements, the positive associations were found for leg length and LLSR while the negative associations were observed for head length and head length-stature ratio.

\section{Thyroid hormones}

An obvious direct relationship was observed between T3 and T4 levels $(\mathrm{r}=0.39, \mathrm{p}<0.01)$. An inverse association between T3/T4 index and biacromial index was found (Table 3 ), and a similar relation has been reported for chest breadth [6]. No relations could be established here between the thyroid hormone concentrations and fat patternings (BW, BMI, \% BF).

\section{Insulin}

These obese women had morning serum insulin levels of $9.8 \pm$ $5.8 \mathrm{mU} / \mathrm{L}$, indicative of normal concentrations, despite individual levels ranging widely from 1.9 to $31.3 \mathrm{mU} / \mathrm{L}$. Insulin as a postprandial

Table 3. Coefficients of partial correlation between age, anthropometric characters and indices and hormonal and metabolic features in obese women.

\begin{tabular}{|c|c|c|c|c|}
\hline \multicolumn{2}{|c|}{ Pair of variables } & \multirow{2}{*}{$\begin{array}{c}\mathbf{n} \\
59\end{array}$} & \multirow{2}{*}{$\begin{array}{c}\mathbf{r} \\
0.26\end{array}$} & \multirow{2}{*}{$\begin{array}{c}\mathbf{p} \\
0.050 \mathrm{Age}=\text { const }\end{array}$} \\
\hline IRI & $-\mathrm{BMI}$ & & & \\
\hline & -WHR & 59 & 0.47 & 0.001 Age, $\mathrm{BMI}=\mathrm{const}$ \\
\hline T3/T4 & - biacromial index & 60 & -0.30 & 0.018 Age, $\mathrm{BMI}=\mathrm{const}$ \\
\hline Glucose & $e$ - age & 60 & 0.38 & $0.003 \mathrm{BMI}=\mathrm{const}$ \\
\hline & $-\mathrm{CWR}$ & 60 & -0.41 & 0.005 Age, $\mathrm{BMI}=\mathrm{const}$ \\
\hline & $-\mathrm{CHR}$ & 60 & -0.27 & 0.041 Age, $\mathrm{BMI}=\mathrm{const}$ \\
\hline & - WHR & 60 & 0.25 & 0.050 Age, $\mathrm{BMI}=\mathrm{const}$ \\
\hline TG & - age & 59 & 0.24 & $0.049 \mathrm{BMI}=\mathrm{const}$ \\
\hline \multirow[t]{2}{*}{ FFA } & $-\mathrm{CWR}$ & 50 & 0.31 & 0.029 Age, $\mathrm{BMI}=\mathrm{const}$ \\
\hline & & & -0.350 & 0.006 Age, $\mathrm{BMI}=\mathrm{const}$ \\
\hline
\end{tabular}

Significant correlations are presented only. 
hormone is known to relate statistically and causally with the amount of body fat and BFD patterns. Central obesity is known to associate with higher fasting and glucose-stimulated insulinemia in women. We found that morning insulin levels positively related to BMI and WHR (Table 3). It seems likely that the association between insulin and age $(\mathrm{r}=0.26, \mathrm{p}<0.05)$ is mediated via total and abdominal fat stores because the control for the effects of BMI and WHR alters the correlation $(\mathrm{r}=0.18$ and $\mathrm{r}=0.16$, respectively, $\mathrm{p}=\mathrm{ns}$ in both cases).

It is advisable to present data here on moderate but not significant associations between insulin levels and BW $(r=0.23, \mathrm{p}<0.08), \% \mathrm{BF}$ $(\mathrm{r}=0.23, \mathrm{p}<0.07)$, and CWR $(\mathrm{r}=-0.22, \mathrm{p}<0.09)$. Insulin was found to be related with basal TG $(\mathrm{r}=0.41, \mathrm{p}<0.01)$, glucose $(\mathrm{r}=0.32, \mathrm{p}<0.05)$, and cortisol levels $(\mathrm{r}=0.35, \mathrm{p}<0.05)$ in these subjects.

\section{Metabolic features}

The age-dependence of glucose levels, found in this study (Table 3 ), is supported by the data from clinical endocrinological practice. Interestingly, glucose concentration shows the opposite relations to anthropometric indices calculated for chest circumference (CWR $\mathrm{r}=-0.41$, CHR $\mathrm{r}=-0.27$ ) and for waist circumference (WHR $\mathrm{r}=0.25$ ). An inverse association was observed between glucose and FFA concentrations $(\mathrm{r}=-0.62, \mathrm{p}<0.0001)$ that is in agreement with modern knowledge of physiological and biochemical mechanisms underlying the regulation of metabolism.

Although there are numerous epidemiologic and observational data suggesting that WHR values are positively associated with TC and TG levels, no correlations were found here in Siberian obese women between WHRs and blood lipids but weak relations were observed for CHRs (TG r $=0.26, \mathrm{p}<0.06$; TC $\mathrm{r}=0.22$, $\mathrm{p}<0.09$ ). TG levels increased with age $(\mathrm{r}=0.24, \mathrm{p}<0.05)$. CWR was the only fat patterning index relating to FFA levels. BMIs did not relate with TG and TC concentrations.

\section{Response to fasting}

Changes of hormonal and metabolic variables in response to 4-and 7-day fasting are reported in Table 4. Although the paired t-test yielded no significant difference between the points, it is evident from the visual analysis of the data that 7-day fasting tended to normalize some of the parameters tested probably due to a metabolic adaptation to short-term starvation. At the 4-day point there were more marked internal perturbations associated with so-called 'acidic crisis' and characterized by increased heart rate, decreased blood $\mathrm{pH}$, and by the shift of the blood acid-base balance to metabolic acidosis [23]. Thus, venous blood $\mathrm{pH}$ indices were $7.308 \pm 0.042,7.253 \pm 0.063$ and $7.259 \pm$ 0.059 , heart rates were $66 \pm 5,74 \pm 7$ and $71 \pm 7$ beats/min at baseline, 4 -day and 7-day fast period, respectively. Therefore, the 4 -day point was considered more suitable for assessing the stress responsiveness, and that is why the analysis below concerns the 4-day fasting only.

Cortisol as a stress hormone and a hyperglycemic regulator increased after the 4-day fasting $(+23.5 \%)$ whereas insulin, which is a glucose counterregulator and postprandial hormone, decreased $(-43.2 \%)$. A widely documented fast-induced fall of T3 level $[24,25]$ is in agreement with the recognized view considering thyroid hormones the stimulators of energy and intermediate metabolism. Similarly, the opposite behavior of TG, FFA and glucose concentrations is well understood based on our knowledge of the mechanisms underlying the adaptation to fasting. Thus, the fasting raised TG (+34.2\%), FFA $(+79.0 \%)$ and lowered glucose concentrations $(-27.4 \%)$. The stressinduced changes in T4 levels, TC and urea concentrations were uncertain and statistically nonsignificant because of the marked between-subject variation (d-T4, range, -54 to $159 \mathrm{nmol} / \mathrm{L}$; d-TC, range, -2.60 to $2.00 \mathrm{mmol} / \mathrm{L}$; d-urea, range, -5.20 to $4.78 \mathrm{mmol} / \mathrm{L}$ ).

\section{Determinants for changes in hormonal and metabolic variables}

The fast-induced changes in TGs and glucose levels demonstrated the similar inverse correlations with age (Figure 1A, B) despite the opposite directions of changes in the concentrations of these substances (Table 4). Although TC showed nonsignificant average increment in response to metabolic stress, $\mathrm{d}-\mathrm{TC}$ value was negatively associated with age (Figure 1C) as glucose and TGs were. Numerically, d-glucose values were $-1.03 \pm 0.55$ and $-1.40 \pm 0.60 \mathrm{mmol} / \mathrm{L}$ in $25^{\text {th }}$ and $75^{\text {th }}$ percentiles for age, respectively $(\mathrm{p}<0.05), \mathrm{d}-\mathrm{TG}$ values were $0.28 \pm 0.30$ and -0.01 $\pm 0.30 \mathrm{mmol} / \mathrm{L}(\mathrm{p}<0.02), \mathrm{d}$-TC values were $0.37 \pm 0.71$ and $-0.19 \pm$ $0.88 \mathrm{mmol} / \mathrm{L}$, respectively $(\mathrm{p}<0.05)$. As in women younger than 41 years TG levels elevated, in aging subjects the levels did not change or even fell (Figure 1A). This finding suggests that aging obese women, at least up to the 50 years, respond to fasting by the marked fall of glucose levels and by the diminished increment or fall of TG levels, thus demonstrating a rigid capacity of adequate metabolic adaptation to total fasting.

The fast-induced decrease in T3 levels directly correlated with CHR $(\mathrm{r}=0.30, \mathrm{p}<0.05)$. This means that the decrease in the hormone level was greater in women with lower BFD than in those having trunkal BFD. Thus, subjects from the highest $\mathrm{CHR}$ quartile $(\mathrm{CHR}>=0.90$, upper obesity) had d-T3 values equal to $-0.32 \pm 0.52 \mathrm{nmol} / \mathrm{L}$, whereas women from the lowest quartile $(\mathrm{CHR}<=0.80$, gluteo-femoral obesity phenotype) had the hormone changes equal to $-0.61 \pm 0.36 \mathrm{nmol} / \mathrm{L}$ $(\mathrm{p}<0.05)$. Table 5 summarizes the correlations between the baseline hormonal and metabolic parameters and their responses to fasting.

The regression analysis revealed that the fasting raised the FFA over the mean baseline in women with the basal level of FFA less than

Table 4. Response of hormonal and biochemical characters to acute fasting in overweight women (Mean \pm SD).

\begin{tabular}{|c|c|c|}
\hline Variable & \multicolumn{2}{|c|}{ Duration of fasting, days } \\
\hline & 0 (baseline) & 4 \\
\hline Plasma cortisol, $\mathrm{nmol} / \mathrm{L}$ & $538 \pm 110(64)$ & $666 \pm 246(52) * * *$ \\
\hline Serum IRI, $\mathrm{mU} / \mathrm{L}$ & $9.78 \pm 5.80(59)$ & $5.55 \pm 4.92(59) * * *$ \\
\hline Serum T3, $\mathrm{nmol} / \mathrm{L}$ & $1.39 \pm 0.47(60)$ & $0.93 \pm 0.46(60) * * *$ \\
\hline Serum T4, $\mathrm{nmol} / \mathrm{L}$ & $104.0 \pm 31.8(60)$ & $111.8 \pm 51.2(60)$ \\
\hline $\mathrm{T} 3 / \mathrm{T} 4$ & $0.014 \pm 0.006(60)$ & $0.009 \pm 0.004(60) * * *$ \\
\hline Blood glucose, $\mathrm{mmol} / \mathrm{L}$ & $4.60 \pm 0.52(60)$ & $3.34 \pm 0.55(54) * * *$ \\
\hline Serum TG, $\mathrm{mmol} / \mathrm{L}$ & $0.76 \pm 0.25(50)$ & $1.02 \pm 0.34(49) * * *$ \\
\hline Serum FFA, $\mathrm{mmol} / \mathrm{L}$ & $0.62 \pm 0.30(50)$ & $1.11 \pm 0.31(49) * * *$ \\
\hline Serum TC, $\mathrm{mmol} / \mathrm{L}$ & $5.45 \pm 1.13(60)$ & $5.63 \pm 1.12(55)$ \\
\hline Serum $u r e a, \mathrm{mmol} / \mathrm{L}$ & $5.80 \pm 1.70(46)$ & $6.02 \pm 1.86(48)$ \\
\hline
\end{tabular}

$* * \mathrm{P}<0.01, * * * \mathrm{P}<0.001$ vs baseline (paired t-test). 

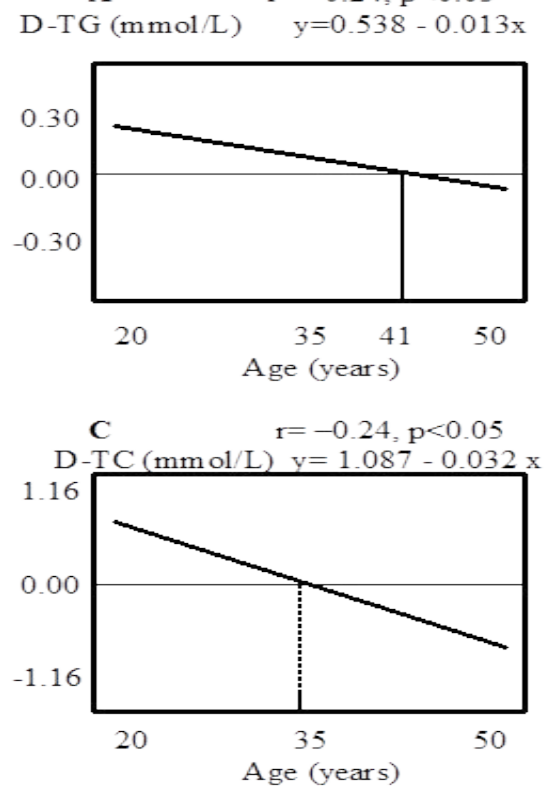

E

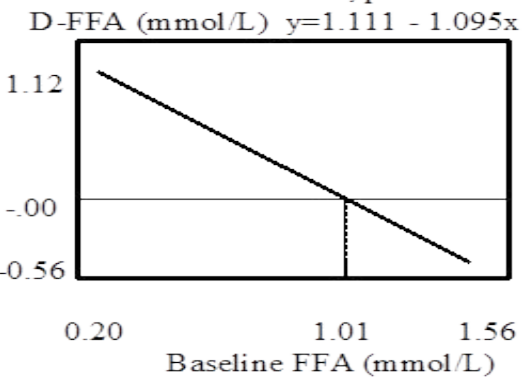

B $\quad \mathrm{r}=-0.32, \mathrm{p}<0.01$

D-glucose $(\mathrm{mmol} / \mathrm{L}) \quad \mathrm{y}=-0.797-0.015 \mathrm{x}$

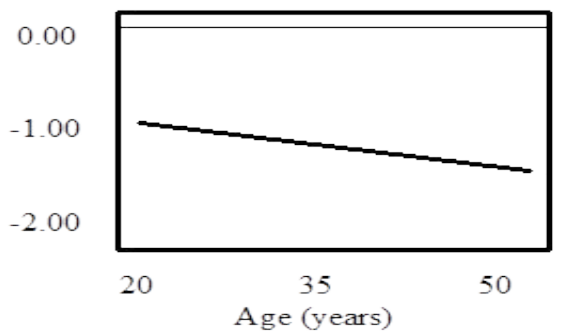

D $\quad \mathrm{r}=-0.65, \mathrm{p}<0.001$

$\mathrm{D}-\mathrm{glucose}(\mathrm{mmol} / \mathrm{L}) \mathrm{y}=-0.861-0.911 \mathrm{x}$

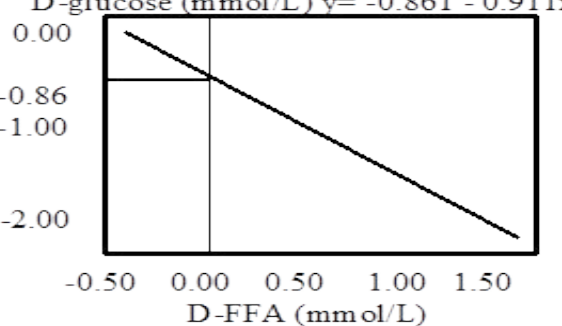

F

$\mathrm{r}=-0.75, \mathrm{p}<0.001$

D-IRI $(\mathrm{mU} / \mathrm{L}) \quad \mathrm{y}=4.332-0.876 \mathrm{x}$

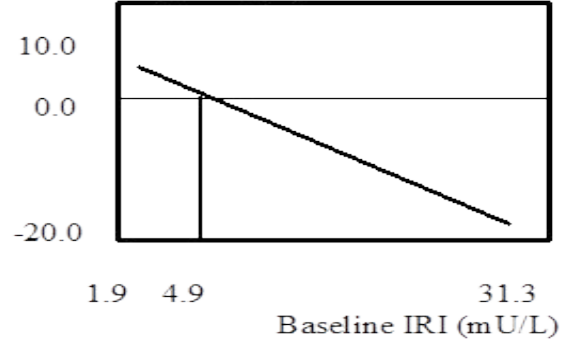

Figure 1. Regression lines and correlations for selected parameters changing in response to 4-day fasting in overnight women. D, delta, difference between fast value and baseline.

$1.01 \mathrm{mmol} / \mathrm{L}$ and lowered it in subjects with the initial value of more than $1.01 \mathrm{mmol} / \mathrm{L}$ (Figure 1E) Similarly, insulin activity was increased in women having the basal one less than $4.9 \mathrm{mU} / \mathrm{L}$ (18.0\% of subjects) and was decreased in women with the initial value of more than 4.9 $\mathrm{mU} / \mathrm{L}$ (Figure 1F). It is evident from the comparison of the Figure s $1 \mathrm{E}$ and $1 \mathrm{~F}$ that the regression lines are similar irrespective of a direction of fast changes (mean d-FFA $>0$, mean $d-I R I<0$ ). The FFA increments were raised with decreasing basal urea concentrations.

The changes in glucose level were directly related to the basal FFA levels (Table 5) indicating that the fast glucose decrease was greater in women with low initial FFA concentrations than in subjects with the high basal FFA levels. The inverse correlation that observed between d-glucose and d-FFA levels (Figure 1D) is obvious since these variables are known to respond consecutively to fasting as resources providing the energy metabolism. As it is derived from linear regression model (Figure 1D), the glucose decrease of $-0.86 \mathrm{mmol} / \mathrm{L}$ is a threshold for fast FFA increase. This value corresponds to $4.60-0.86=3.74 \mathrm{mmol} / \mathrm{L}$ of absolute fast glucose level. In other words, in the sample, the FFA levels are increased during the 4 -day fast period $(\mathrm{d}-\mathrm{FFA}>0)$ in women having the blood glucose levels less than $3.74 \mathrm{mmol} / \mathrm{L}$. This study can provide the basic information for further dynamic researches.

The fast changes of all hormonal and biochemical variables, except that of TG and thyroxin, are inversely related to the respective baseline levels thus confirming the concept of basimetry [26]. Changes in TG and T4 levels were nonsignificantly but again negatively correlated with the basal levels of the parameters ( $r=-0.13$ and $\mathrm{r}=-0.08$, respectively).

The correlation analysis yielded the weak and slightly significant relations between basal T4 and TC levels $(r=-0.25, p<0.055)$, basal T3 and TG levels $(r=-0.26, p<0.066)$, initial T4 and d-glucose levels $(\mathrm{r}=0.26, \mathrm{p}<0.057)$, basal cortisol and $\mathrm{d}-\mathrm{TC}$ levels $(\mathrm{r}=0.26, \mathrm{p}<0.064)$, $\mathrm{d}$-cortisol and basal urea concentrations $(\mathrm{r}=0.25, \mathrm{p}<0.1)$.

\section{Anthropometric, hormonal and metabolic correlates for weight loss}

As a group, during the 27-day WLP the women lost a significant amount of their body weight $(-7.3 \pm 3.1 \%, \mathrm{p}<0.01)$. The relative BW changes were predicted by the percentage of trunk fat. A direct ageindependent correlation (partial $\mathrm{r}=0.35, \mathrm{p}<0.01$ ), illustrated by the regression line in Figure 1A, suggests that women with increased percentages of trunk fat had increased d-BW and therefore low BW decreases. (Analyzing the quite complicated relations observed, one should take into consideration that, in case of negative fast changes of a variable $(\operatorname{delta}<0)$, the $\mathrm{d}$-value is inversely associated with the absolute decrease of the parameter.)

Other direct relations of $\% \mathrm{BW}$ changes with age (rho $=0.33$, $\mathrm{p}<0.01)$, WHR $(\mathrm{r}=0.26, \mathrm{p}<0.05)$, and \%TSF $(\mathrm{r}=0.25, \mathrm{p}<0.05)$, however, disappeared when the effects of the percentage of trunk fat were controlled in a partial correlation analysis. No correlations could be 
Table 5. Spearman correlation coefficients between hormonal and biochemical variables at baseline and after 4-day acute fasting in obese women.

\begin{tabular}{|c|c|c|c|}
\hline Pair of parameters & $\mathrm{n}$ & $\mathrm{r}$ & $\mathrm{p}$ \\
\hline $\begin{array}{l}\text { Cortisol - } \\
\text { d-cortisol }\end{array}$ & 57 & -0.33 & 0.012 \\
\hline$-\mathrm{d}-\mathrm{TG}$ & 46 & 0.34 & 0.021 \\
\hline$-\mathrm{d}-\mathrm{IRI}$ & 54 & -0.74 & 0.000 \\
\hline$-\mathrm{d}-\mathrm{T} 3$ & 60 & -0.48 & 0.000 \\
\hline $\begin{array}{l}\text { Glucose - } \\
\text { d-glucose }\end{array}$ & 56 & -0.64 & 0.000 \\
\hline- FFA & 49 & -0.55 & 0.000 \\
\hline -d-FFA & 49 & 0.37 & 0.009 \\
\hline - IRI & 58 & 0.34 & 0.008 \\
\hline D-glucose - FFA & 47 & 0.64 & 0.000 \\
\hline -d-FFA & 47 & -0.65 & 0.000 \\
\hline- FFA & 45 & -0.31 & 0.041 \\
\hline$-\mathrm{d}-\mathrm{T} 4$ & 53 & -0.28 & 0.042 \\
\hline -d-FFA & 50 & -0.74 & 0.000 \\
\hline - urea & 41 & 0.42 & 0.007 \\
\hline$-\mathrm{T} 4$ & 49 & 0.29 & 0.042 \\
\hline$-\mathrm{d}-\mathrm{T} 3$ & 49 & 0.31 & 0.030 \\
\hline D-FFA - urea & 41 & -0.30 & 0.050 \\
\hline$-\mathrm{d}-\mathrm{TC}$ & 60 & -0.36 & 0.004 \\
\hline -d-FFA & 50 & -0.28 & 0.048 \\
\hline$-\mathrm{T} 3$ & 59 & -0.38 & 0.003 \\
\hline -d-IRI & 58 & -0.38 & 0.003 \\
\hline Urea - d-urea & 46 & -0.46 & 0.001 \\
\hline
\end{tabular}

Significant correlations are presented only. D, delta, difference between fast value and baseline. IRI: immunoreactive insulin; T3: triiodthyronin; T4: thyroxin; TC: total cholesterol, TG: triglycerides, FFA: free fatty acids.

observed in these subjects between relative weight loss and the degree of obesity as assessed by the BMI and \% of body fat. The inverse correlations of d-BW with LLSR $(r=-0.34, \mathrm{p}<0.01)$, CWR $(\mathrm{r}=-0.28$, $\mathrm{p}<0.05)$, the $\%$ of body muscle $(\mathrm{r}=-0.27, \mathrm{p}<0.05)$, and the $\%$ of thigh fat $(r=-0.27, p<0.05)$ became weak and nonsignificant after allowing for the impacts of age.

As for biochemical and hormonal variables, the percent changes in BW positively correlated with 4-day fast-baseline difference in FFA levels $(\mathrm{r}=0.31, \mathrm{p}<0.03)$ and $\mathrm{d}$-urea $(\mathrm{r}=0.22, \mathrm{p}<0.1)$, and correlated negatively with basal FFA $(r=-0.33, p<0.02)$, T4 levels $(r=-0.31$, $\mathrm{p}<0.02)$, and with $\mathrm{d}-\mathrm{TG}$ values $(\mathrm{r}=-0.25, \mathrm{p}<0.07)$. In other words, the magnitudes of weight reduction are greatest in women with increased basal FFA, T4 levels, with enhanced fast-induced TG elevation, and with diminished fast increment in serum urea and FFA levels.

The observational analysis revealed that subjects from the lowest CHR quartile, having gynoid or gluteo-femoral BFD, as compared to upper trunk obese counterparts from the highest quartile, showed more marked unfavorable response to 7-day total fasting assessed either by subjective patients' self-reports (headache, vertigo, tremor) and by objective characteristics (cases of hypertension and transient complication in hepatobiliary system, acetonic odor). These latter findings are to be regarded as tentative until more extensive data and statistical confirmation are available.

\section{Discussion}

In our study, CHR was found to be a powerful predictor for morning plasma cortisol level. The basal cortisol does not correlate with WHR as it has also been reported in hirsute women [27]. No differences in the blood basal hormone concentrations were shown in normal obese women [11] and in women with polycystic ovary syndrome [5] grouped by WHR. CHR is found here to predict morning cortisol levels in Siberian obese women. To explain the correlation we supposed that subcutaneous adipocytes from the upper-trunk and gluteofemoral regions had differential responsiveness to metabolic stimuli, direct or mediated, of glucocorticoids and/or other factors associated with the hormones.

The bases of the hypothesis are as follows. The experimental data exist on the permissive action of glucocorticoids on catecholamineinduced lipolysis [28] which in turn is known to be regional dependent $[29,30]$. The administering of cortisol increased the subcutaneous abdominal adipocytes volume [31] and decreased the cell's size in the gluteal region [32]. The hypothesized differential metabolic behavior of upper-trunk and gluteofemoral adipose tissues may be due to differing cell size in these regions since the lipolysis activity depends on fat cell size rather than on region of origin [33].

One more elucidation of the cortisol-BFD correlation in functional hypercortisolism is that the upper-trunk fat preponderance appears to correlate with adrenal hyperandrogenecity as it has been established for female android type of obesity $[27,34,35]$. Region-specific differential activity of cortisol-metabolizing enzymes [36] and sensitivity to glucocorticoids [37] may play a key role in determining BFD in functional or constitutional hypercortisolism.

Changes in body muscle regional distribution patterns could not be entirely eliminated from the causal analysis of the cortisol influences on anthropometric traits because of the known data on muscle atrophy occurring predominantly and in the first place in pelvic girdle and gluteofemoral region in patients with Itsenko-Cushing's syndrome [38]. The involvement of this mechanism in the relation described here between cortisol and CHR would be quite probable in case if an inverse relation of the hormone level with hip circumference occurred.

Other clinical findings may explain the relation observed in this study between the cortisol and BFD patterns. Thus, pathognomonic anthropometric symptoms of severe hypercortisolism in patients suffering from Itsenko-Cushing's syndrome are known. These are the decrease in gluteofemoral fat mass [39] and small thigh circumference [40], the round "moon-like" face, fat accumulation in the neck, the suprascapular region and in the shoulder girdle. Taken as a whole these anthropometric features characterize the particular "cushingoid" type of obesity. Although increased waist girth is a part of this complex, it is not a cardinal symptom of hypercortisolism and may accompany such hormonal abnormalities as adrenal (in women) and/or ovarian hyperandrogenecity, insulin resistance, NIDDM, and growth hormone deficiency [41].

It would be tempting to enter data on the glucocorticoid-induced leptin resistance $[42,43]$ and on the elevation of leptin level in patients with Cushing's syndrome [44,45], confirmed by the experiments in vitro [46], but no association was found between leptin levels and BFD patterns [47].

These studies make the above supposition quite reasonable, but unfortunately and again, were carried out on the fat tissue from abdominal region only. In this respect, we suppose that early studies of Vague [1] and his numerous followers limited the research field by the abdominal adipocytes whereas, at least for basal cortisol level, there is another powerful somatometric predictor, CHR. Since correlation does not imply causality, our finding, established in a cross-over study, may be used as a background for working hypotheses for intervention researches.

Our study does not confirm the observations that various stress tests (physical, mental, cold) induce a more pronounced cortisol 
response in subjects with high WHR than in those with a lower WHR $[13,48]$. We could not establish a relation between 4 -day fast-induced cortisol increments and somatometric traits, including WHR, probably due to differences between fast metabolic disturbances and other kinds of stress investigated elsewhere. Furthermore, all performed stress experiments lasted for no longer than an hour whereas in our study subjects were fasting over four days.

Two anthropometric indices, the \% of body muscle and the \% of thigh fat, unexpectedly showed the similar statistical behavior and correlated negatively with insulin activity, TGs, TC levels and changes in BW, whereas indicators of centripetal BFD (WHR, the \% of trunk fat) were associated directly with weight loss, insulin activity and parameters of lipid metabolism. In the previous study of obese women we have reported the opposed correlations, independent of age and $\mathrm{BMI}$, of venous blood $\mathrm{pO} 2$ values with the $\%$ of thigh fat $(\mathrm{r}<0)$ and the $\%$ of trunk fat $(r>0)$ [23]. Similarly, BMI was found to correlate positively with the $\%$ of trunk fat and correlate negatively with the $\%$ of leg fat in girls aged 4-16 years [49]. A trunk-extremity contrast in skinfold thicknesses was shown to be the only fat pattern that was homogeneous across Black and White males and females, and that explained a major part of the total variance in subcutaneous fat distribution [50]. It seems likely from these findings that the behavior of thigh fat differs from those of trunk one and is statistically similar to those of muscle tissue, and the respective correlations of the $\%$ of thigh fat with the $\%$ of trunk fat $(r=-0.56)$ and the $\%$ of body muscle $(r=0.56)$ were established here.

Furthermore, there are indirect statistical evidences, revealed by correlation analysis, of the distinguished metabolic behavior of adipose tissues from the upper and middle regions of the trunk. These evidences are as follows. We found in these subjects the opposite correlations of CHRs and WHRs with basal glucose levels $(r<0$ and $r>0$, respectively, Table 2), BMIs ( $r=-0.26$ and $r=0.23$, respectively), and BW $(r=-0.25$ and $r=0.22$, respectively). These findings suggest that abdominal fat, both visceral and subcutaneous fat considered together, differed metabolically not only from the gluteofemoral fat, as it has been reported [51], but also from the upper-trunk adipose tissue at least as far as glucose metabolism is concerned. The differences established between relations of CHRs and WHRs may be due to the involvement of omental fat size into the waist circumference.

In order to explain the weak inverse correlation between CHR and $\mathrm{BMI}$ it is reasonable to assume that there is a physical limitation of adipose tissue accumulation in the upper part of the trunk, which may be associated with the dangerous rise of the body's center of gravity and decrease of the equilibrium steadiness of the body. There was previously described a predominant reduction in waist circumference when compared with hip after WLP for women with abdominal BFD but not for those with gluteofemoral BFD [52]. These findings were confirmed by the in vitro biochemical investigations of glucose and lipid metabolism patterns in human adipocytes from abdominal and gluteal regions [53].

The data on the relationship between thyroid hormone levels and body fat patterns are somewhat confusing. Thus, negative correlations occurred between BW, BMI and T3 concentrations [24] whereas in other works a direct correlation was found $[6,54]$. In the present study performed on the Siberian sample no correlations of the anthropometric variables and indices with the thyroid hormones measured could be observed except those of the \% of thigh fat. In general, it should be noted from the data available from the euthyroid subjects that relations of thyroid hormone levels with anthropometric traits are not as reliable as those of cortisol, insulin, and sex hormones.

A secretion of thyroid hormones is influenced by the state of nutrition [55]. Thus, underfeeding and fasting induce a decrease in the
T3 level in lean [56,57] and obese [58] women, the same is shown in our study. Moreover, consistent correlations were found here between fast-induced T3 decrements and the parameters of trunk-thigh fat contrast, viz. CHR, \% trunk fat, and \% thigh fat (Table 4). It is evident from modern literature that the role of thyroid hormones in the control of body shape and BFD in healthy subjects has probably yet to be investigated. On the other hand, the effects of thyroid hormones secretion disturbances on growth, body size, and anthropometric traits in mixodema, cretinism, and Graves' disease are known.

In our study the magnitude of weight loss slightly increased with increasing basal urea levels $(\mathrm{r}=0.28, \mathrm{p}<0.06)$ and with decreasing fast-induced changes in urea concentration. On the other hand, the sample mean urea level was not elevated significantly in response to 4-day fasting, whereas such elevation should be expected. To explain this discrepancy, at least two suppositions may be considered. First, 4-day fasting is not too long to activate a protein catabolism and amino acids oxidation because of increased fat stores and enhanced lipid oxidation. Thus, in the sample, the fast-induced urea elevation showed the weak and slightly significant inverse correlation with basal BW $(\mathrm{r}=-0.28, \mathrm{p}<0.06)$ and BMI $(\mathrm{r}=-0.27, \mathrm{p}<0.07)$ indicating that urea synthesis in response to fasting diminished with increasing total fatness. Furthermore, an oxidation of labeled leucine was found to correlate inversely with lipid oxidation in obese women [59]. Second, the metabolic acidosis, existing in these subjects at the fast state [23], may result in a decrease in urea synthesis due to an inhibition of amino acids transport across the liver plasma membranes as it has been shown in rats with acute $\mathrm{HCl}$-induced metabolic acidosis [60].

Although the amount of visceral adipose tissue has been reported to be related to the parameters of protein metabolism [59], in our investigation no statistical associations were found between urea levels and BFD patterns including waist girth and WHR. In general, serum urea concentrations both in basal state and after fasting exhibited the least correlations with the somatometric, hormonal, and biochemical variables measured probably due to a marked individual variability.

In contrast to what has been observed in Japanese women for TC [61] and in German women for TGs [62], no relations between these substances and WHR could be established in Siberian sample population but weak correlations exist between them and CHRs. It has been reported that basal cortisol level was independent of BMI $[5,12,27]$ whereas in this study the correlation occurred. The causes of these differences remain to be explained.

It is evident from a comparison of our data with those previously reported $[27,52]$ that WHR is a more effective predictor for the patterns of lipid and glucose metabolism than CHR, but the latter index has the more predictive power for the morning cortisol compared with the first one. On the other hand, HPA axis responsiveness to stress and pharmacological stimulation or suppression depends on WHR [14]. The lack of correlation between CHR and WHR was observed in our study. It can be argued that they are predominantly determined by the amount of subcutaneous fat tissue for CHR and by the size of greater omentum (i.e. abdominal visceral adipocytes) for WHR. The indices are not synonymous and therefore they can be used to define the different obesity phenotypes - android by WHR and cushingoid by CHR. Unfortunately, we cannot answer whether or not CHR as a somatometric predictor of hormonal and metabolic parameters is peculiar to Siberian obese women only because nobody examined this index elsewhere.

In conclusion, our observational study provides statistical evidence that increased blood glucocorticoid levels within the physiological 
limits relate to the development of upper body fat accumulation in obese fertile women. In this respect, CHR could be considered an early somatometric predictor of hypercortisolism in endocrinologically healthy obese women when other indices of the disorder are still absent.

\section{Acknowledgment}

We are greatly indebted to Drs. O.I. Kuzminova and E.L. Astrakhantseva for biochemical, hormonal and anthropometric measurements.

\section{References}

1. Vague J (1956) The degree of masculine differentiation of obesities: a factor determining preposition to diabetes, atherosclerosis, gout, and uric calculous disease. Am J Clin Nutr 4: 20-34. [Crossref]

2. Jensen MD (1997) Health consequences of fat distribution. Horm Res 48 Suppl 5: 8892. [Crossref]

3. Kahn HS, Austin H, Williamson DF, Arensberg D (1996) Simple anthropometric indices associated with ischemic heart disease. J Clin Epidemiol 49: 1017-1024. [Crossref]

4. Björntorp P (1996) The origins and consequences of obesity. Diabetes. Ciba Found Symp 201: 68-80. [Crossref]

5. Pasquali R, Casimirri F, Venturoli S, Antonio M, Morselli L, et al. (1994) Body fat distribution has weight-independent effects on clinical, hormonal, and metabolic features of women with polycystic ovary syndrome. Metabolism 43: 706-713.

6. Kirchengast S (1994) Body dimensions and thyroid hormone levels in premenopausal and postmenopausal women from Austria. Am J Phys Anthropol 94: 487-497. [Crossref]

7. Kirchengast S (1993) Anthropometric-hormonal correlation patterns in fertile and postmenopausal women from Austria. Ann Hum Biol 20: 47-65. [Crossref]

8. Noppe G, van den Akker EL, et al. (2016) Long-term glucocorticoid concentrations as a risk factor for childhood obesity and adverse body-fat distribution. Int J Obes (Lond) 40: 1503-1509. [Crossref]

9. Ceccato F, Boccato M, Zilio M, Barbot M, Frigo AC, et al. (2017) Body Composition is Different After Surgical or Pharmacological Remission of Cushing's Syndrome: A Prospective DXA Study. Horm Metab Res 49: 660-666. [Crossref]

10. Tirabassi G, Muscogiuri G, Colao A, Balercia G (2016) Dysregulation of the hypothalamic-pituitary-adrenal axis increases central body fat accumulation in males affected by diabetes mellitus and late-onset hypogonadism. Endocr Pract 22: 427-433. [Crossref]

11. Pasquali R, Cantobelli S, Casimirri F, Capelli M, Bortoluzzi L, et al. (1993) The hypothalamic-pituitary-adrenal axis in obese women with different patterns of body fat distribution. J Clin Endocrinol Metab 77: 361-366. [Crossref]

12. Vicennati V, Calzoni F, Gambineri A, Gagliardi L, Labate ARM, et al. (1998) Secretion of major adrenal androgens following ACTH administration in obese women with different body fat distribution. Horm Metab Res 30: 133-136. [Crossref]

13. Mårin P, Darin N, Amemiya T, Andersson B, Jern S, et al. (1992) Cortisol secretion in relation to body fat distribution in obese premenopausal women. Metabolism 41: 882-886. [Crossref]

14. Fernández-Real JM, Ricart W, Casamitjana R (1997) Lower cortisol levels after oral glucose in subjects with insulin resistance and abdominal obesity. Clin Endocrinol (Oxf) 47: 583-588. [Crossref]

15. Pasquali R, Anconetani B, Chattat R, Biscotti M, Spinucci G, et al. (1996) Hypothalamicpituitary-adrenal axis activity and its relationship to the autonomic nervous system in women with visceral and subcutaneous obesity: effects of the corticotropin-releasing factor arginine-vasopressin test and of stress. Metabolism 45: 351-356. [Crossref]

16. Sharp DS, Andrew ME, Fekedulegn DB, Burchfiel CM, Violanti JM, et al. (2013) The cortisol response in policemen: intraindividual variation, not concentration level, predicts truncal obesity. Am J Hum Biol 25: 499-507. [Crossref]

17. Incollingo Rodriguez AC, Epel ES, White ML, Standen EC, Seckl JR, et al. (2015) Hypothalamic-pituitary-adrenal axis dysregulation and cortisol activity in obesity: A systematic review. Psychoneuroendocrinology 62: 301-318. [Crossref]

18. Strain GW, Zumoff B, Kream J, Strain JJ, Levin J, Fukushima D (1982) Sex differences in the influence of obesity on the 24-hr mean plasma concentration of cortisol. Metabolism 31: 209-212. [Crossref]
19. Durnin JVGA, Womersley J (1974) Body fat assessed from total density and its estimation from skinfold thicknesses: Measurements on 481 men and women aged from 16 to 72 years. Br J Nutr 32: 77-97. [Crossref]

20. Neri BP, Frings CS (1973) Improved method for determination of triglycerides in serum. Clin Chem 19: 1201-1202. [Crossref]

21. Itaya K, UI M (1965) Colorimetric determination of free fatty acids in biological fluids. J Lipid Res 6: 16-20. [Crossref]

22. Lemieux S, Prudhomme D, Bouchard C, Tremblay A, Despres JP (1996) A single threshold value of waist girth identifies normal-weight and overweight subjects with excess visceral adipose tissue. Am J Clin Nutr 64: 685-693. [Crossref]

23. Melnikov VN, Kim LB, Shorin YP, Shukolyukova EL, Selyatitskaya VG, et al. (1998) Relations between anthropometric characteristics and blood acid-base balance patterns in obese women. Visnik Vinnitskogo Derzhavnogo Med Universitetu 2: 170-171.

24. Buscemi S, Verga S, Maneri R, Blunda G, Galluzzo A (1997) Influences of obesity and weight loss on thyroid hormones. A 3-3.5-year follow-up study on obese subjects with surgical bilio-pancreatic by-pass. J Endocrinol Invest 20: 276-281. [Crossref]

25. KmieÄ $\ddagger$ Z, Kotlarz G, Smiechowska B, MyÅsliwski A (1998) The effect of fasting and refeeding on thyroid follicule structure and thyroid hormone levels in young and old rats. Arch Gerontol Geriatr 26: 161-175. [Crossref]

26. Wilder J (1962) Basimetric approach (law of initial value) to biological rhythms. Ann N Y Acad Sci 98: 1211-1220. [Crossref]

27. Hauner H, Ditschuneit HH, Pal SB, Moncayo R, Pfeiffer EF (1988) Fat distribution, endocrine and metabolic profile in obese women with and without hirsutism. Metabolism 37: 281-286. [Crossref]

28. Lacasa D, Acli B, Ciudicelli Y (1988) Permissive action of glucocorticoids on catecholamine-induced lipolysis: direct in vitro effects on the fat cell ?-adrenoreceptorcoupled-adenylate cyclase system. Biochem Biophys Res Comm 153: 489-497. [Crossref]

29. Smith U (1984) Regional differences in adipocyte metabolism and possible consequences in vivo. In Recent advances in obesity research IV - Proc. 4th Intern. Congress on Obesity. London: Libbey pp: 33-36.

30. Jensen MD (1997) Lipolysis: contribution from regional fat. Annu Rev Nutr 17: 127139. [Crossref]

31. Vague J, Vague P, Combes R (1978) Cortisol and testosterone effect on adipose tissue cellularity in man. In Crepadi G, Lefebvre PJ, Alberti K (eds.) Diabetes, obesity and hyperlipidemias. New York: Academic pp: 159-167.

32. Krotkiewski M, Blohmé B, Lindholm N, Björntorp P (1976) The effects of adrenal corticosteroids on regional adipocyte size in man. J Clin Endocrinol Metab 42: 91-97. [Crossref]

33. Reynisdottir S, Dauzats M, Thorne A, Langin D (1997) Comparison of hormonesensitive lipase activity from visceral and subcutaneous human adipose tissue. $J$ Clin Endocrinol Metab 82: 4162-4166. [Crossref]

34. Evans DJ, Hoffman RG, Kalkhoff RK, Kissebah AH (1983) Relationship of androgenic activity to body fat topography, fat cell morphology and metabolic abberations in premenopausal women. J Clin Endocrinol Metab 57: 304-310. [Crossref]

35. Remer T, Pietrzik K (1987) Concept of the importance of nutritional status in the regulation of adrenal secretion. J Clin Biochem Nutr 3: 179-187.

36. Westerbacka J, Yki-Järvinen H, Vehkavaara S, Häkkinen AM, Andrew R, et al (2003) Body fat distribution and cortisol metabolism in healthy men: enhanced 5betareductase and lower cortisol/cortisone metabolite ratios in men with fatty liver. $J$ Clin Endocrinol Metab 88: 4924-4931. [Crossref]

37. Duclos M, Gatta B, Corcuff JB, Rashedi M, Pehourcq F, et al. (2001) Fat distribution in obese women is associated with subtle alterations of the hypothalamic-pituitary-adrenal axis activity and sensitivity to glucocorticoids. Clin Endocrinol 55: 447-454. [Crossref]

38. Muller R, Kugelberg E (1959) Myopathy in Cushing's syndrome. J Neurol Neurosurg Psychiatry 22: 314-319. [Crossref]

39. Manolopoulos KN, Karpe F, Frayn KN (2010) Gluteofemoral body fat as a determinant of metabolic health. Int J Obes (Lond) 34: 949-959. [Crossref]

40. Wagenmakers M, Roerink S, Gil L, Plantinga T, Smit J, et al. (2015) Persistent centripetal fat distribution and metabolic abnormalities in patients in long-term remission of Cushing's syndrome. Clin Endocrinol (Oxf) 82: 180-187. [Crossref]

41. Bjrntorp P (1997) Endocrine abnormalities in obesity. Diabetes Rev 5: 52-68. 
42. Ur E, Grossman A, Després JP (1996) Obesity results as a consequence of glucocorticoid induced leptin resistance. Horm Metab Res 28: 744-747. [Crossref]

43. Robaczyk MG (2002) Evaluation of leptin levels in plasma and their reliance on other hormonal factors affecting tissue fat levels in people with various levels of endogenous cotisol. Ann Acad Med Stetin 48: 283-300. [Crossref]

44. Robaczyk M, Krzyzanowiska-Swiniarska B, Andrysiak-Mamos E, Kulig G, Pilarska K (2003) Plasma leptin levels in relation to body composition and body fat distribution in patients with Cushing's syndrome. Pol Arch Med Wewn 110: 1299-1308.

45. Valassi E, Biller BM, Klibanski A, Misra M (2012) Adipokines and cardiovascular risk in Cushing's syndrome. Neuroendocrinology 95: 187-206. [Crossref]

46. Halleux CM, Servais I, Reul BA, Detry R, Brichard SM (1998) Multihormonal control of ob gene expression and leptin secretion from cultured human visceral adipose tissue: increased responsiveness to glucocorticoids in obesity. J Clin Endocrinol Metab 83: 902-910.

47. Solin MS, Ball MJ, Robertson I, de Silva A, Pasco JA, et al. (1997) Relationship of serum leptin to total and truncal body fat. Clin Sci (Lond) 93: 581-584. [Crossref]

48. Moyer AE, Rodin J, Grilo CM, Cummings N, Larson LM, et al. (1994) Stress-induced cortisol response and fat distribution in women. Obes Res 2: 255-262. [Crossref]

49. Taylor RW, Cannan R, Gold E, Lewis-Barned NJ, Goulding A (1996) Regional body fat distribution in New Zealand girls aged 4-16 years: a cross-sectional study by dual energy X-ray absorptiometry. Int J Obes Relat Metab Disord 20: 763-767. [Crossref]

50. Baumgartner RN, Roche AF, Guo S, Lohman T, Boileau RA, et al. (1986) Adipose tissue distribution: the stability of principal components by sex, ethnicity and maturation stage. Hum Biol 58: 719-735.

51. Kather H, Zöllig K, Simon B, Schlierf G (1977) Human fat cell adenylate cyclase: regional differences in adrenaline responsiveness. Eur J Clin Invest 7: 595-597. [Crossref]

52. Dennis KE, Goldberg AP (1993) Differential effects of body fatness and body fat distribution on risk factors for cardiovascular disease in women. Impact of weight loss. Arterioscler Thromb 13: 1487-1494. [Crossref]
53. Cigolini M, Bonora E, Querena M, Moghetti P, Cacciatori V, et al. (1988) Differences in glucose metabolism enzyme activities in human adipose tissue from abdominal and gluteal regions. Metabolism 37: 820-823. [Crossref]

54. Raschka C (1991) Bezüge zwischen konstitutionellen anthropometrischen Kengr?ssen und individuellen Hormonspiegeln bei Ausdauersportlern-Morphoendokrinologische Korrelationen. Wiss. Z. Humbolt-Univ. Berlin. 40: 132-141.

55. Hendler R, Bonde AA (1988) Very-low-calorie diets with high and low protein content impact on triiodothyronine, energy expenditure, and nitrogen balance. Am J Clin Nutr 48: 1239-1247. [Crossref]

56. Unger J (1988) Fasting induces a decrease in serum thyroglobulin in normal subjects. $J$ Clin Endocrinol Metab 67: 1309-1311. [Crossref]

57. Beer SF, Bircham PMM, Bloom SR, Clark PM, Hales CN, et al. (1989) The effect of a 72-h fast on plasma level of pituitary, adrenal, thyroid, pancreatic and gastrointestinal hormones in healthy men and women. J Endocrinol 120: 337-350. [Crossref]

58. Phinney SD, LaGrange BM, O'Connell M, Danforth E Jr (1988) Effects of aerobic exercise on energy expenditure and nitrogen balance during very low calorie dieting. Metabolism 37: 758-765. [Crossref]

59. Solini A, Bonora E, Bonadonna R, Castellino P, Defronzo RA (1997) Protein metabolism in human obesity: relationship with glucose and lipid metabolism and with visceral adipose tissue. J Clin Endocrinol Metab 82: 2552-2558. [Crossref]

60. Boon L, Blomaart PJE, Meijer AJ, Lamers WH, Schoolwerth AC (1996) Response of hepatic amino acid composition to chronic metabolic acidosis. Am J Physiol 40: F198-F202.

61. Tanaca H, Kakiyama T, Takahara K, Yamauchi M, Tanaka M, et al. (1995) The association among fat distribution, physical fitness, and the risk factors of cardiovascular disease in obese women. Obes Res 5: s649-s653. [Crossref]

62. Hollmann M, Runnebaum B, Gerhard I (1997) Impact of waist-hip-ratio and bodymass-index on hormonal and metabolic parameters in young, obese women. Int J Obes Relat Metab Disord 21: 476-483. [Crossref]

Copyright: (C2017 Melnikov VN. This is an open-access article distributed under the terms of the Creative Commons Attribution License, which permits unrestricted use, distribution, and reproduction in any medium, provided the original author and source are credited. 